\title{
ANÁLISE EXPLORATÓRIA ATRAVÉS DE ESTATÍSTICA ESPACIAL: UM ESTUDO DE CASO NA RESERVA BIOLÓGICA DO TINGUÁ
}

\author{
Débora Querino da Silva ${ }^{(a)}$, Gustavo Mota de Sousa ${ }^{(b)}$ \\ (a) Departamento de Geociências /IA, Universidade Federal Rural do Rio de Janeiro, deboraquerino94@gmail.com \\ (b) Departamento de Geociências/IA, Universidade Federal Rural do Rio de Janeiro, gustavobond@gmail.com
}

Eixo: Uso e ocupação das terras e legislação ambiental

\begin{abstract}
Resumo
As unidades de conservação contêm conflitos relacionados às suas áreas, pois, mesmo com todo o conhecimento dos gestores acerca das áreas das unidades, estas ainda não possuem um mapeamento e definição atualizados. O objetivo deste estudo é entender como se dão os conflitos na unidade de conservação e contribuir para com a construção de um mapeamento de densidade de infrações ambientais. Obteve-se, para tanto, uma análise das áreas frágeis no limite da Reserva Biológica do Tinguá, sendo possível ser percebido que as zonas frágeis se apresentam prioritariamente nas bordas; e nas estradas imperiais e nas vias utilizadas por empreendimentos no interior da Reserva. E os locais protegidos, nos lugares de altitude e declividade, nos quais se apresentam floresta densa e protegida.
\end{abstract}

Palavras chave: Kernel estimator; Reserva biológica do Tingua; Infrações ambientais.

\section{Introdução}

A Reserva Biológica do Tinguá (REBIO Tinguá) é reconhecida como a maior reserva biológica da Mata Atlântica existente no Estado do Rio de Janeiro e tem importância porque conserva em seu território trechos importantes de biodiversidade que correspondem a $8 \%$ das florestas protegidas. Por esta razão, se encontra inserida na Reserva da Biosfera da Mata Atlântica - RBMA que é reconhecida pela Organização das Nações Unidas para a Educação, a Ciência e a Cultura - UNESCO (MARTINS, 2016). Além disso, é importante ressaltar que a REBIO Tinguá realiza a proteção de remanescentes de floresta localizados dentro de municípios que compõem a Região Metropolitana do Rio de Janeiro - RMRJ e Serrana.

Para uma área ser categorizada como Reserva Biológica, se faz necessário apresentar um ecossistema de importância notável, ter espécies endêmicas de fauna e flora e as mesmas serem frágeis, contendo diversidade biológica; ou seja, um local onde é necessária a conservação e, ademais, ser pertencente ao poder público (ICMBIO, 2002) (SNUC, 2000).

Além dos remanescentes florestais, a Reserva possui em seus interiores mananciais que são responsáveis pela sua construção histórica e, principalmente, pelo abastecimento de água de parte da RMRJ, pois há captações da Companhia Estadual de Águas e Esgotos do Rio de Janeiro - CEDAE. Segundo Souza 
(2003), deve-se proteger as florestas que fazem parte da REBIO Tinguá visando também à proteção dos mananciais de água que começou em 1833, pois a área foi doada ao Império e foi decretado como área de proteção integral dos seus atributos naturais.

Contudo, como uma Unidade de Proteção Integral instituida a partir do Sistema Nacional de Unidades de Conservação - SNUC -, esta apresenta inúmeros conflitos. A implatação de uma Unidade de Conservação pode gerar dissenções pois esta é criada para manter controle sobre determinada área e recurso ambiental (GUERRA et al., 2009). Atualmente, os conflitos ambientais que mais se destacam são: ocupação irregular, invasão e caça e os grandes empreendimentos de empresas que tem interface com o território protegido como a Concer, Transpetro, CEDAE e Furnas. Os conflitos são caracterizados como Infrações Ambientais - Lei no 9.605/1998, pois se tratam de atos que infringem leis de proteção, recuperação, entre outras.

As infrações ambientais são geradas em coordenadas geográficas; ou seja, são gerados pontos para todo ato contra os objetivos para a qual a REBIO Tinguá foi criada. Esses pontos não associados a valores em si, mas apenas ocorrências serão utilizadas mediante a metodologia de análise espacial, utilizando kernel estimator para analisar o comportamento dos pontos e estimar os aglomerados espaciais (cluster).

Diante do exposto, o objetivo desse trabalho é entender como se dão os conflitos na unidade de conservação e contribuir com a construção de um mapeamento de densidade de infrações ambientais. E, por fim, analisar as áreas frágeis nos limites da REBIO Tinguá.

\section{2. Área de estudo}

A Reserva Biológica do Tinguá se localiza no Estado no Rio de Janeiro tendo sua área situada em sua maioria nos municípios da Região Metropolitana. Compreende uma área de 26.260 hectares, aproximadamente 0,6\% do Estado do Rio de Janeiro (IBAMA, 2006). Os municípios que a compõem são Nova Iguaçu (55,14\%), Duque de Caxias (37,44\%), Petrópolis (4,26\%) e Miguel Pereira (3,16\%), de Japeri e Queimados, estes últimos estão presentes na Zona de Amortecimento (ZA) como é apresentado na Figura 1. 


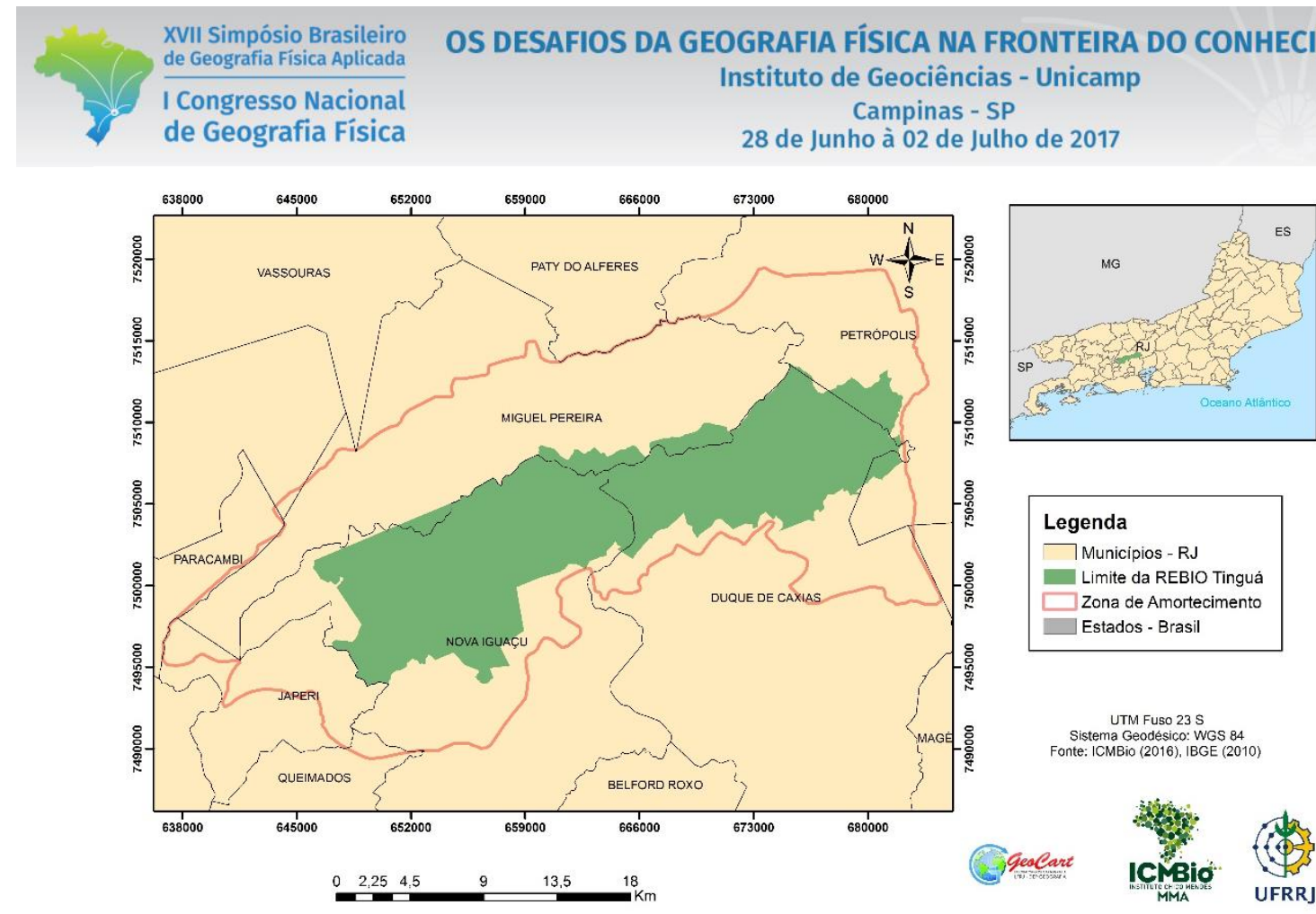

Figura 1: Reserva Ecológica do Tinguá.

A história dessa Unidade de Conservação e de sua proteção da unidade atual é intimamente relacionada com o abastecimento de água, pois em 1833 D. Pedro II decretou que os mananciais que estavam em terras da região do Tinguá fossem protegidos, com o intuito de abastecer a cidade do Rio de Janeiro, visto que esta já estava com o abastecimento precário devido aos desmatamentos na Floresta da Tijuca.

Em 1941, Tinguá foi protegido pelo código florestal vigente, sendo conhecida como Floresta Protetora da União Tinguá, Xerém e Mantequira. Entretanto, o que fez a UC ter sua área protegida foi a declividade e a altitude que impossibilitaram uma possível ocupação de seu território (SANTOS, 2016). Devido ao aumento das pressões antrópicas, em 1989 através do Decreto no. 97.780 de 23 de maio de 1989, a Reserva Biológica do Tinguá é criada a fim de "proteger amostra representativa da floresta de encosta atlântica, com sua flora, fauna e demais recursos naturais, em especial os recursos hídricos" (BRASIL, 1989).

\section{Metodologia}

A metodologia para realização deste trabalho consiste na divisão do mesmo em etapas, sendo elas: a obtenção de dados através do Instituto Chico Mendes de Conservação da Biodiversidade (ICMBio); processamentos dos dados; aplicação de estatística espacial; e análise dos resultados. A metodologia aplicada pode ser vista no fluxograma apresentada na figura 2. 


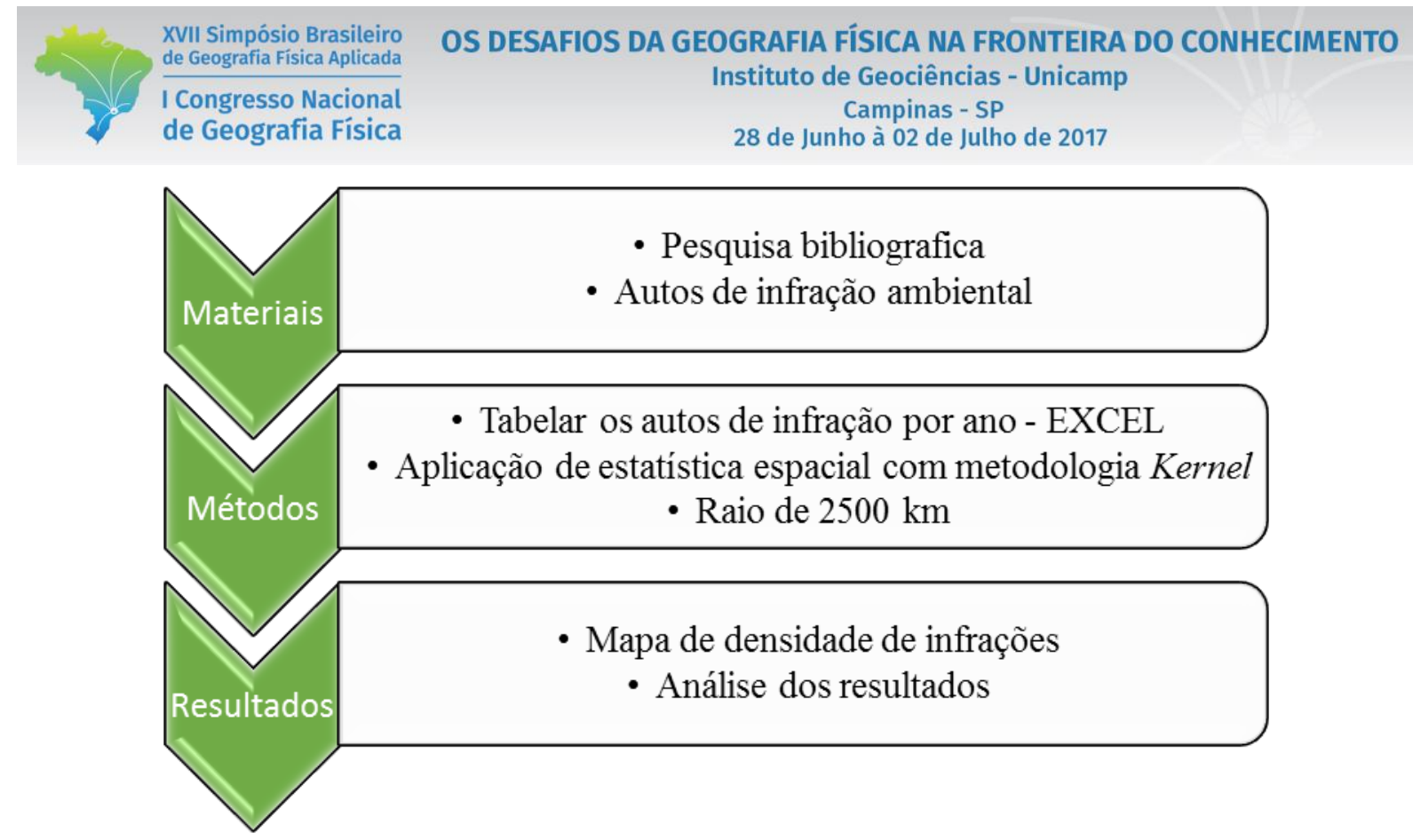

Figura 2 - Fluxograma metodológico

Os materiais utilizados no trabalho foram disponibilizados pelo ICMBio em forma de fichas padronizadas de auto de infração que contém os dados do autuado, descrição da infração, coordenadas, artigo da infração, valor da multa, entre outros. De acordo com a demanda de atividades conflitantes, são geradas autuações discutidas neste trabalho. Maia (2016) define que um auto de infração ambiental se trata de um documento no qual o responsável legal, ou seja, um agente de fiscalização do Instituto, autua certificando que há ilícitos no interior da UC, conforme definição por decreto ou em área que cause impacto à Reserva. Neste documento administrativo, é indicada penalidade e/ou medida de mitigação do dado de acordo com a infração constatada. A partir desses autos, é possível obter a espacialização dos mesmos na Reserva a partir de estatística espacial.

As autuações foram agrupadas de acordo com série temporal de 2012 até 2015, e os artigos correspondentes editados em planilhas que indicaram a posição espacial definida por meio de coordenadas geográficas. Esse procedimento possibilitou a inserção da planilha com dados referentes às infrações realizadas com a possibilidade de observação com outros dados espaciais verificados em software de Sistema de Informações Geográficas. No período determinado, a Reserva Biológica do Tinguá realizou 269 autuações das quais 12 são infrações contra a fauna, 25 infrações contra a flora, 43 relativas e à poluição e outras infrações ambientais e 164 cometidas exclusivamente em UC. (Tabela I) 


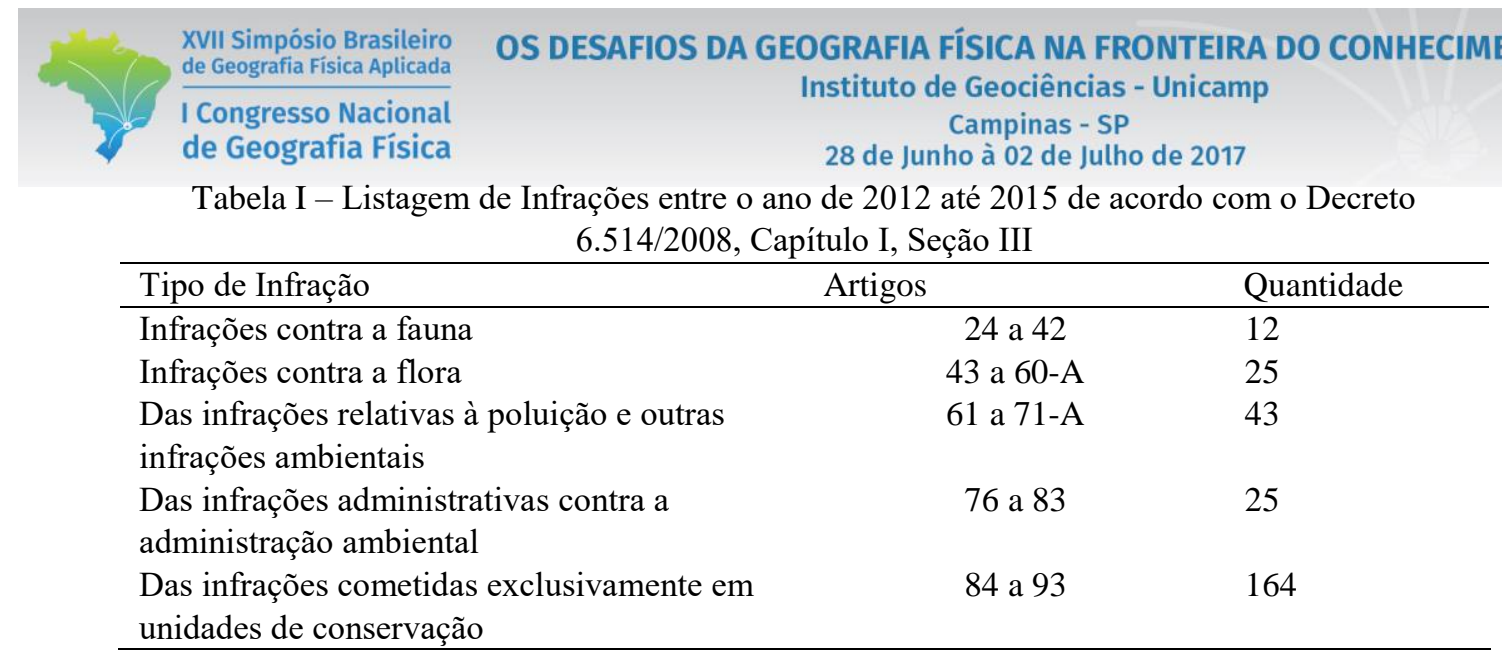

As infrações são enquadradas de acordo com um artigo sendo também realizadas observações quanto a estas. As infrações contra a fauna na área de estudo são em sua maioria coletar, transportar e manter em cativeiro fauna silvestre. São apreendidos em sua maioria pássaros, pois é um habito comum entre os moradores do entorno tê-los.

As infrações contra a flora resumem-se em destruir ou danificar florestas, receber ou adquirir produtos florestais, impedir ou dificultar a regeneração natural de florestas e comercializar espécies de mata atlântica. Nota-se na área que a maior parte das infrações são de destruir ou danificar floresta nativa. Já nas infrações relativas à poluição e outras infrações ambientais são predominantemente construir ou reformar, seja uma ocupação irregular ou uma obra da CEDAE ou PETROBRAS, sem autorização do órgão ambiental para ser realizada.

Ainda sobre as infrações, há a infração contra a administração ambiental. Em sua maioria, são infrações a empresas e pessoas por não cumprir embargos e notificações legais, e/ou dificultarem a ação do poder público. No que diz respeito àquelas cometidas exclusivamente em unidades de conservação, se observa um grande número de autuações acerca da realização de quaisquer atividades ou de adoção de conduta em desacordo com os objetivos da unidade de conservação, o seu plano de manejo e regulamento. A maioria destes indivíduos utiliza a reserva para a realização de práticas religiosas.

As autuações são demonstradas no mapa a seguir em forma de pontos (Figura 2). Podemos perceber que essas se dão próximos a vias existentes na Reserva. O que provoca locais de fragilidade na Unidade de Conservação. As vias existentes na Reserva são duas estradas construídas no Império, chamadas de Caminho do imperador e Estrada Real do Comércio (PLANO DE MANEJO, 2006). Além de arruamentos irregulares abertos pela população que reside irregularmente na área, dutos da Petrobras, vias de acesso as captações da CEDAE, a BR- 040 e Furnas. 


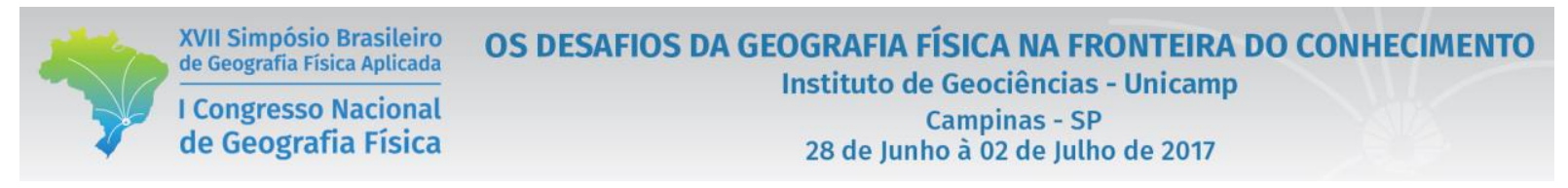

Outra característica a ser abordada são as autuações estarem nas bordas da unidade de conservação, onde começa a zona de amortecimento. Isso se dá pelo avanço da urbanização no entorno.

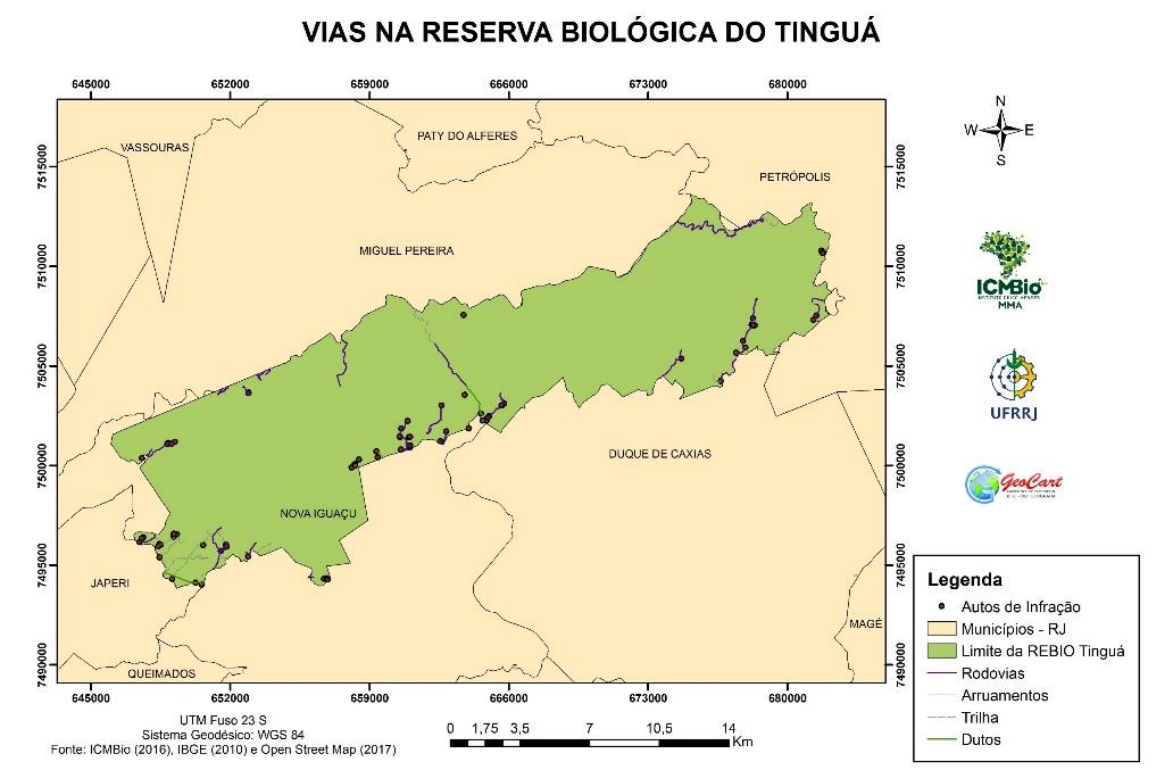

Figura 3 - Mapa de vias de acesso a Rebio Tinguá

Os dados de infrações consistem em uma série de coordenadas de pontos dispersos nos limites da REBIO Tinguá que trouxeram a possibilidade de obtenção das concentrações das autuações por meio do uso de estatística espacial baseada em Kernel. Para isso, foi utilizada a ferramenta kernel estimator, disponível no ArcGIS 10.1, que se trata de um interpolador que fornece a distribuição geral de um evento, pois mostra a superfície onde estão as maiores concentrações e decresce para a menores concentrações. Segundo DRUCK (2004), este estimador funciona de acordo com parâmetros básicos: o raio de influência que define a vizinhança e a função $\mathrm{K}$ que estima a intensidade. Este estimador é relatado pelo mesmo autor como uma metodologia muito útil para fornecer a visão de distribuições pontuais demonstrando em quais localidades concentram-se as maiores intensidades.

$\mathrm{O}$ raio de influência definido utilizado é $2,5 \mathrm{~km}$ e se adequou aos objetivos da área de estudo, gerando pontos de intensidade e evitando resultados como a formação de um raio pequeno com pequenos círculos sem continuidade, ou de um raio grande demais formando um único ponto de intensidade (DRUCK et al., 2004).

A geração da interpolação das autuações por Kernel possibilitou a sobreposição desses resultados com outras variáveis espaciais provenientes da Geomorfologia que são a altitude e a declividade, além do Uso do TOPODATA para gerar os mapas de altitude e declividade. 


\section{Resultados e discussões}

As infrações discutidas apresentam como resultado um mapa de densidade de infração do ano de 2012 até 2015 (Figura 2). Apesar dos pontos demonstrarem facilmente onde se encontram as infrações, eles podem ser ocultados de acordo com a escala de estudo e a sobreposição das ocorrências em muitos casos. Desta forma, se utiliza estatística espacial a fim de demostrar as áreas onde há um aglomerado de eventos.

Na legenda se utilizou a nomenclatura de muito baixa, baixa, média, alta e muito alta para facilitar o entendimento do mapeamento para população em geral. Em um raio de 2,5 quilômetros:

\section{DENSIDADE DE AUTUAÇÕES DE INFRAÇÕES AMBIENTAIS}

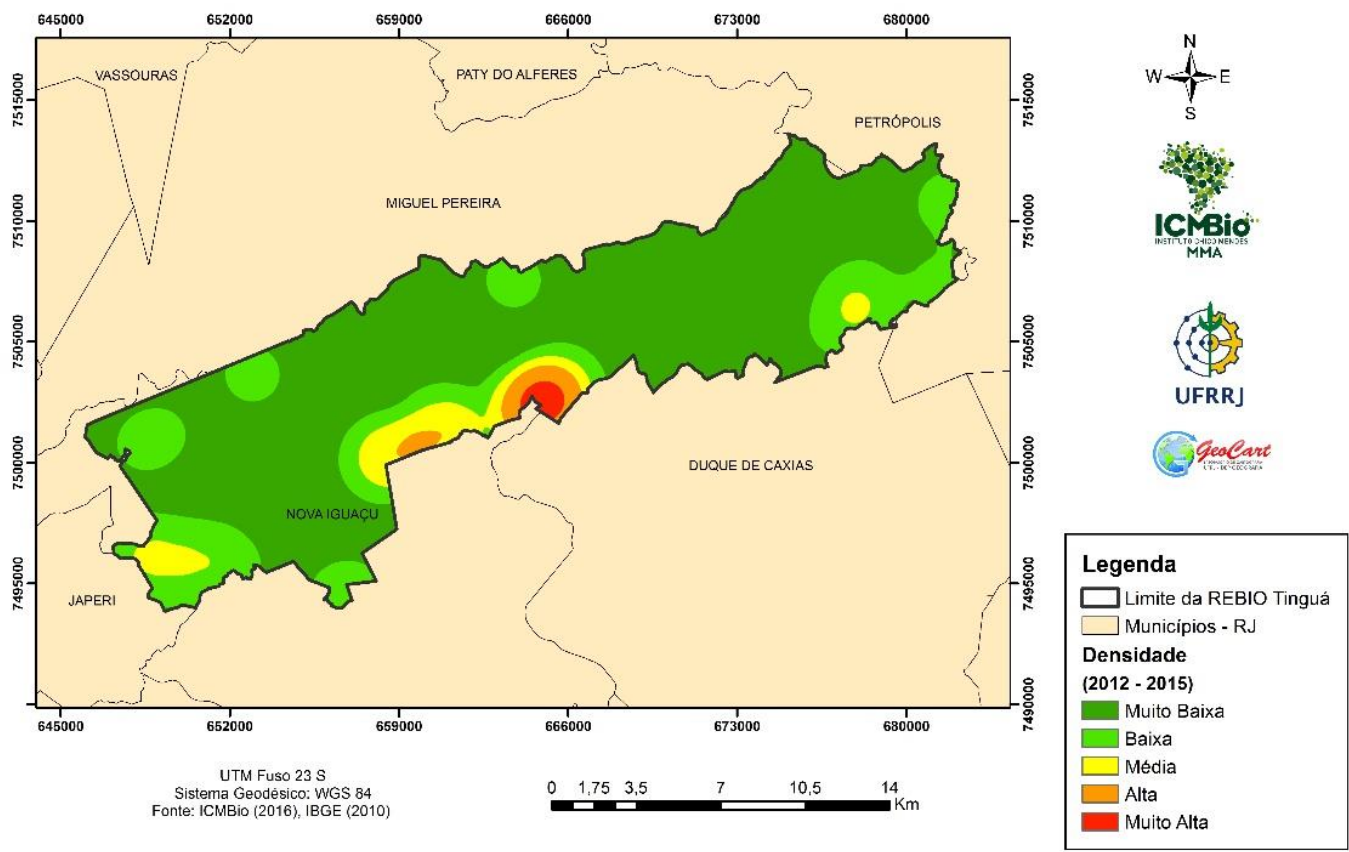

Figura 4 - Mapa de densidade de infração ambiental

Analisando o mapa de densidade de autuações (Figura 4), nota-se que as áreas classificadas como alta e muito alta se apresentam em localidades próximas no município de Nova Iguaçu. Já a área mais densa se localiza no bairro de Tinguá, onde se localiza a sede da REBIO. As autuações dessa localidade dão-se pela proximidade da Reserva com um bairro denso causando o fácil acesso desse ponto por religiosos que fazem seus cultos na UC, pessoas em atividades de lazer como cachoeiras próximas ao centro desse bairro e as ocupações irregulares que se encontram dentro da área a ser preservada. 


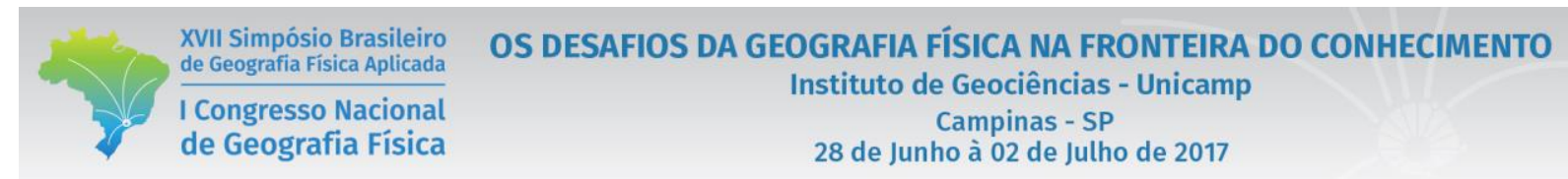

As áreas com densidade média a oeste também dentro do município de Nova Iguaçu na divisa com Japeri. Nessa localidade a maior pressão realizada na Reserva é de imóveis irregulares. Esse avanço se dá nos limites imediatos das áreas preservadas e cria uma fragilidade na borda esquerda da Reserva, acarretando em outros problemas nas encostas e nas matas ciliares.

A densidade média a leste se encontra no município de Duque de Caxias, no distrito de Xerém que apresenta autuações de diferentes tipos como a ameaça contra a fauna, a flora, imóveis irregulares e inúmeras medidas contra a CONCER, empresa que administra a BR-040 que passa dentro da REBIO Tinguá.

A parte norte em que está localizado o município de Miguel Pereira apresenta vegetação densa, e por este motivo as infrações relacionadas à área são baixas e relacionadas à destruição de mata atlântica e captura de fauna e flora silvestre. Nas áreas onde as autuações são muito baixas é verificado, através do mapa de declividade e altitude, que há altitudes elevadas e com maior declividade que geram difícil acesso externo. Essa característica do Estado do Rio de Janeiro protegeu grande parte da mata Atlântica em período anterior ao surgimento das UC existentes hoje. A maior parte das atuações se encontra a menos de $25^{\circ}$ de declividade e a $300 \mathrm{~m}$ de altitude; ou seja, as regiões montanhosas ainda não são consideradas zonas frágeis. Todavia, na região de altitudes elevadas são verificadas infrações de caça e apreensão, que não são muito controladas dado o difícil acesso até mesmo de físcais do ICMBio.

\section{DECLIVIDADE DA RESERVA BIOLÓGICA DO TINGUÁ}

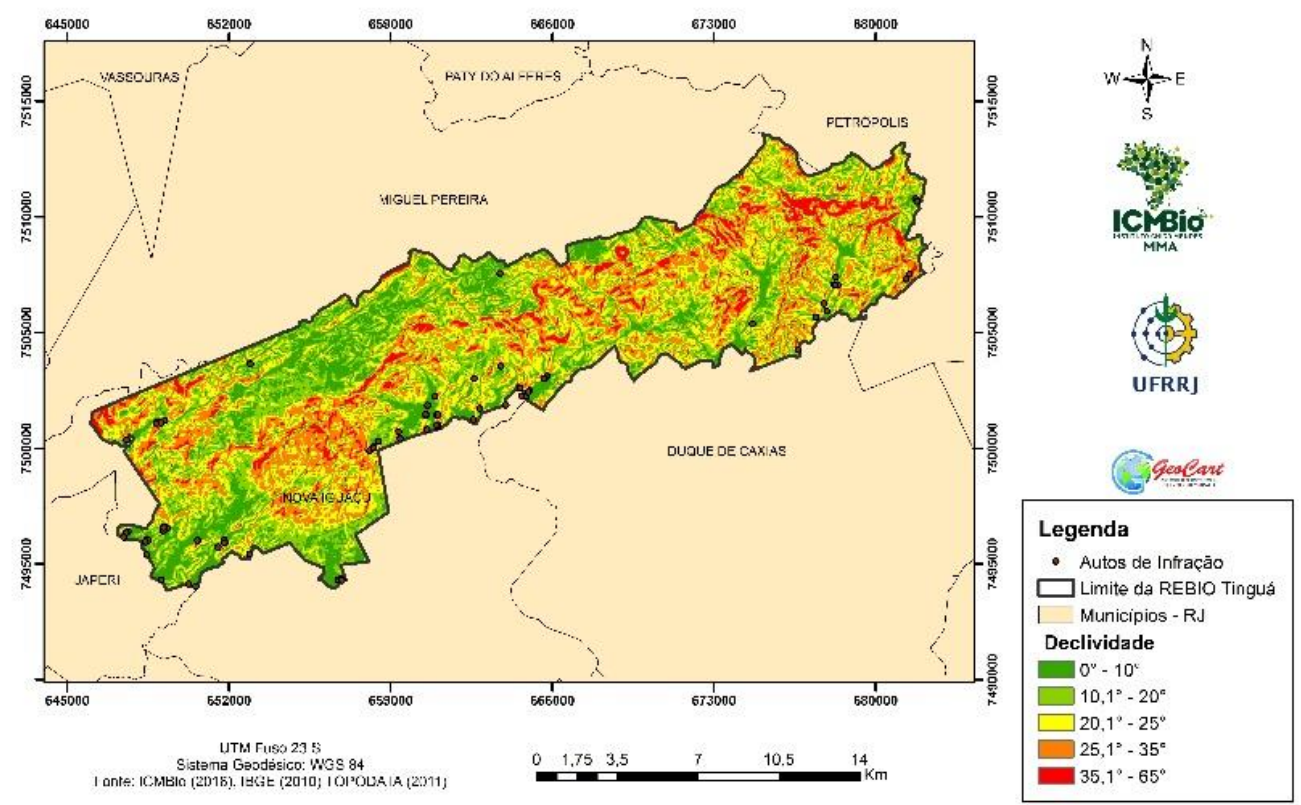

Figura 5 - Mapa de declividade 


\section{ALTITUDE DA RESERVA BIOLÓGICA DO TINGUÁ}

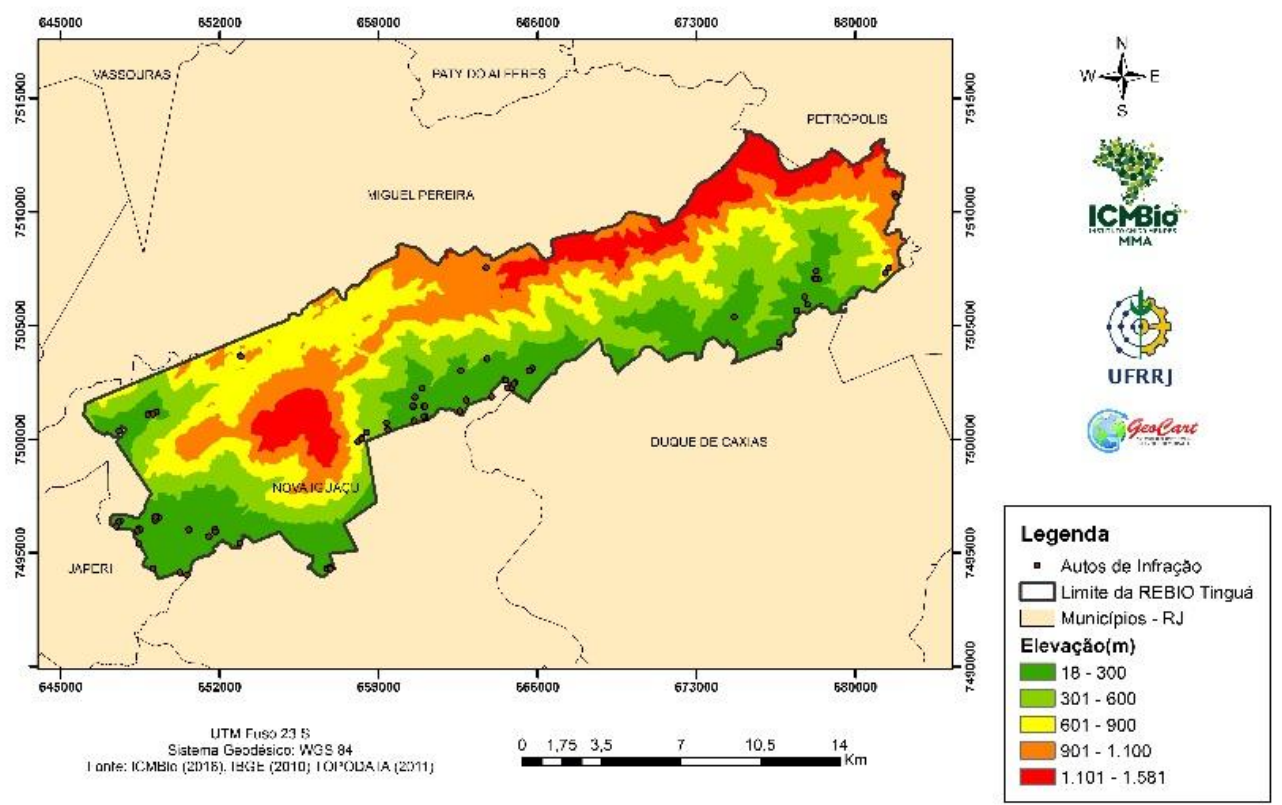

Figura 6 - Mapa de altitude

\section{Conclusão}

Mediante esses estudos, podemos identificar características de zonas mais frágeis na REBIO Tinguá. A zona entre o limite da REBIO e a Zona de amortecimento, as vias de acesso às empresas e estradas antigas se tornam zonas frágeis pelas pressões dos conflitos existentes. As áreas autuadas nesse trabalho são de conhecimento da Gestão e são alvos de constantes discussões em conselhos consultivos (ICMBIO, 2014).

Contudo, as vias - principalmente as que são utilizadas pelas empresas localizadas dentro da UC - devem buscar junto à gestão formas de impedir a entrada de pessoas. E as Secretarias de cada município devem exercer suas funções de planejadores e gestores a fim de coibir o aumento dos imóveis irregulares.

Em um estudo futuro poder-se-á atribuir a cada infração um valor para obtenção de uma estatística espacial diferenciada de acordo com o impacto que cada infração exerce na REBio. Entretanto, o objetivo do trabalho era a utilização de infrações de forma numérica, e não o grau de impacto destas individualmente.

\section{Bibliografia}

BRASIL. Decreto $\mathbf{n}^{0}$ 97.780, de 23 de maio de 1989. Cria a Reserva Biológica do Tinguá, e dá outras providências. Brasília. 1989. 
GUERRA, Antonio José Teixeira; COELHO, Maria Célia Nunes. (Orgs.). Unidades de conservação: abordagens e características geográficas. Rio de Janeiro: Bertrand Brasil, 2009. 57p.

DRUCK, S.; CARVALHO, M.S.; CÂMARA, G.; MONTEIRO, A.V.M. (eds) "Análise Espacial de Dados Geográficos". Brasília, EMBRAPA, 2004

ICMBIO. Guia do Educador. Reserva Biológica do Tinguá, 2002

ICMBIO. Conselhos gestores de unidade de conservação federal Disponível em http://www.icmbio.gov.br/portal/images/stories/comunicacao/publicacoes/guia-conselhos-2014.pdf acessado em 11 de janeiro de 2017

MAIA, Bruno Landim. Condições Mínimas Para A Validade De Um Auto De Infração Ambiental, De Acordo Com O Direito Ambiental Administrativo. Disponível em < http://www.egov.ufsc.br:8080/portal/sites/default

/files/anexos/20085-20086-1-PB.pdf> Acesso em 08/08/2016.

MARTINS, Ana Lucia Lucas. Lazer e área protegida: conflitos na busca de "emoções agradáveis" Disponível em $<$ http://www.scielo.br/scielo.php?script=sci_arttext\&p id=S1414-753X2011000200005 >acesso_em 09/08/2016

IBAMA, 2006. Plano de manejo da Reserva Biológica do Tinguá. Disponível em: http://www.ICMBio.gov.br/portal/biodiversidade/unidades-deconservacao/biomasbrasi

SANTOS, Joyce Pereira Dos. Infrações administrativas ambientais em unidades de conservação: o caso da Reserva Biológica do Tinguá [Rio de Janeiro] 2016. VII pp., 123 pp. Monografia (Curso de Especialização) Escola Nacional de Ciências Estatísticas. Curso Lato Sensu em Análise Ambiental e Gestão do Território.

SNUC - Sistema Nacional de Unidades de Conservação da Natureza - lei ${ }^{\circ}$ 9.985, , de 18 de julho de 2000; decreto $\mathrm{n}^{\circ}$ 4.340, de 22 de agosto de 2002. 6.ed. aum. Brasília: MMA/SBF, 2006. 